\title{
Yawning and stretching predict brain temperature changes in rats: support for the thermoregulatory hypothesis
}

\author{
Melanie L. Shoup-Knox ${ }^{1}{ }^{*}$,Andrew C. Gallup ${ }^{2}$, Gordon G. Gallup Jr. ${ }^{1}$ and Ewan C. McNay ${ }^{1,3}$ \\ Department of Psychology, University at Albany, Albany, NY, USA \\ 2 Department of Biological Sciences, Binghamton University, Binghamton, NY, USA \\ ${ }^{3}$ Center for Neuroscience Research, University at Albany, Albany, NY, USA
}

\author{
Edited by: \\ Jesse Bering, \\ Queens University, Ireland \\ Reviewed by: \\ Cheryl S. Lynch, \\ University of Louisiana, USA. \\ Anne B. Clark, \\ Binghamton University, USA \\ *Correspondence: \\ Melanie L. Shoup-Knox, Evolution and \\ Human Behavior Laboratory, \\ Biopsychology, Department of \\ Psychology, 1400 Washington Avenue, \\ Albany, NY 12222, USA. \\ e-mail:melshoup@gmail.com
}

\begin{abstract}
Recent research suggests that yawning is an adaptive behavior that functions to promote brain thermoregulation among homeotherms. To explore the relationship between brain temperature and yawning we implanted thermocoupled probes in the frontal cortex of rats to measure brain temperature before, during and after yawning. Temperature recordings indicate that yawns and stretches occurred during increases in brain temperature, with brain temperatures being restored to baseline following the execution of each of these behaviors. The circulatory changes that accompany yawning and stretching may explain some of the thermal similarities surrounding these events. These results suggest that yawning and stretching may serve to maintain brain thermal homeostasis.
\end{abstract}

Keywords: yawning, stretching, thermoregulation, brain cooling, brain temperature

\section{INTRODUCTION}

Yawning has been documented in all five classes of vertebrates, suggesting an ancient phylogeny and an essential basic function (Baenninger, 1987), yet the adaptive significance of yawning has yet to be determined (Provine, 2005), and is likely multifunctional across species. A satisfying yawn involves gaping of the mouth, eye closure and watering, salivation, and is often accompanied by stretching (Provine, 1986, 2005). Contrary to popular opinion, yawning is not affected by changes in blood oxygen or carbon dioxide levels. Provine et al. (1987b) showed that neither inhalation of heightened levels of oxygen or carbon dioxide nor physical exercise influenced yawning. Therefore, it seems that yawning does not serve a respiratory function, and that yawning and breathing are controlled by separate mechanisms. Baenninger (1997) suggested that yawning functions to stimulate or facilitate cortical arousal during state change. Consistent with this hypothesis, yawning occurs in anticipation of important events and during behavioral transitions or changes in activity levels across vertebrate taxa. While this account may explain the hedonic quality and unprompted nature of yawning, the particular physiological mechanism mediating such arousal has not been identified. Matikainen and Elo (2008) suggested that arousal could be facilitated by muscular stimulation of the oxygen sensing carotid body during a yawn, but this hypothesis has not been tested.

Recent research suggests that yawning may contribute to brain thermoregulation among homeotherms (reviewed by Gallup, 2010). In humans, medical and physiological literature shows that conditions such as multiple sclerosis, migraine headaches, epilepsy, stress and anxiety, and schizophrenia are all linked with thermoregulatory dysfunction and are often associated with instances of atypical yawning (Gallup and Gallup Jr., 2008; Gallup et al., 2010). One clinical report shows excessive yawning during periods of mild hyperthermia, and body temperature is reduced below baseline levels following yawning bouts (Gallup Jr. and Gallup, 2010). Frequent yawning is symptomatic of conditions that increase brain and/or core temperature, such as central nervous system damage (Krantz et al., 2004; Cattaneo et al., 2006) and the use of selective serotonin reuptake inhibitors (Chen and Lu, 2009). Other drugs that increase brain temperature frequently produce excessive yawning, while drugs that lead to hypothermia inhibit yawning (Argiolas and Melis, 1998). Likewise, dopamine D2 agonists induce hypothermia at high doses, and this corresponds with decreased yawning in rats (Collins et al., 2007). Experimental research on one bird species (Melopsittacus undulatus), has shown that yawning occurs more frequently during rising ambient temperatures (Gallup et al., 2009), and is correlated with other thermoregulatory behaviors such as panting and wing venting (Gallup et al., 2010). Similarly, an observational report of behavioral thermoregulation in capuchins (Cebus capucinus) has shown that yawning occurs more frequently in high ambient temperatures (Campos and Fedigan, 2009). Consistent with these reports, Deputte (1994) documented that yawning among macaques (Macaca fascicularis) was positively correlated with ambient temperature while outside, and that rising temperatures correlated with an increase in yawning frequency while animals were lying down.

The homeothermic brain operates most efficiently within a limited temperature range and is regulated by mechanisms that maintain optimal temperature during periods of hyperthermia (Cabanac, 1993). In humans, brain temperature averages approximately $37^{\circ} \mathrm{C}$, with circadian fluctuations of up to $\pm 0.5^{\circ} \mathrm{C}$ (Landolt et al., 1995). Brain temperature is primarily determined by metabolic heat production, temperature of the blood supply, and rate of blood flow. Physiological cooling mechanisms affecting the blood supply to the brain include convection, conduction, and evaporation. Convection occurs after sweat, mucosal, tear, or saliva evaporation cools cutaneous and subcutaneous venus plexuses in the oral, 
nasal, and paranasal cavities (Zenker and Kubik, 1996), as well as in the ophthalmic veins during hyperthermia (Caputa et al., 1978; Deklunder et al., 1991; Hirashita et al., 1992). Intertwined venous and arterial rete structures enable heat transfer from warm incoming blood to cooled venous blood. Increased blood flow during body stretching, neck and facial stretching, or increased heart rate variability (Greco and Baenninger, 1991; Guggisberg et al., 2007) during yawning may further increase convective brain cooling (Zajonc, 1985; Askenasy, 1989). Heat dissipation through the upper airways allows for additional evaporative cooling. Introduction of cool air into the nasal cavity can effectively lower brain surface temperature (Harris et al., 2006), and during periods of induced mild hyperthermia, nasal breathing produces a rapid $\left(0.1^{\circ} \mathrm{C}\right.$ per minute) drop in frontal lobe temperature of up to $0.8^{\circ} \mathrm{C}$ (Mariak et al., 1999). During a yawn, deep inhalation may similarly invoke evaporative cooling of the venous blood draining from the nasal and oral orifices into the cavernous sinus. This process would effectively cool the area surrounding the internal carotid artery, which supplies blood to the rest of the brain. Nasal breathing (in the absence of jaw closure) inhibits the incidence of yawning in humans (Gallup and Gallup Jr., 2007), suggesting that yawning may be suppressed when the brain is sufficiently cooled by nasal cavity airflow.

Taken together, these results suggest that yawning may activate multiple mechanisms involved in maintaining/reinstating brain thermal homeostasis. According to this model, spontaneous yawning is most likely to occur in response to brain hyperthermia, promoting thermal homeostasis by decreasing brain temperature. Because yawning is often accompanied by neck or arm stretching (Provine et al., 1987a; Daquin et al., 2001; Provine, 2005), stretching may also occur in response to increases in brain temperature independently of yawning. The present study represents a preliminary investigation of the relationship between changes in brain temperature associated with yawning and stretching events in rats (Rattus norvegicus). An indwelling thermocoupled probe was used to continuously record brain temperature in the prelimbic cortex of awake, freely moving rats before, during, and after instances of spontaneous yawning and stretching.

\section{MATERIALS AND METHODS SUBJECTS}

Young adult (300-350 g) male Sprague Dawley rats (Charles River Laboratories, Riverdale, NJ, USA) were used for this study. Four of seven rats exhibited yawning during testing sessions and contributed to the dataset. Animals were kept on a reversed light:dark cycle, housed at a constant $21 \pm 2^{\circ} \mathrm{C}$ and were provided food and water ad libitum. All procedures, including surgery and testing, were approved by the University at Albany Institutional Animal Care and Use Committee.

\section{ANIMAL PREPARATION}

A single microdialysis guide cannula was implanted in the prelimbic cortex of each animal. Standard sterile stereotactic surgeries were performed with the skull position adjusted to horizontal. Cannulae were implanted at $3.7 \mathrm{~mm}$ anterior from bregma, $+0.6 \mathrm{~mm}$ lateral from the midline, and $3.7 \mathrm{~mm}$ ventral from dura, and the positions were verified histologically on completion of the study. Implants were secured in place using at least two cranial screws and dental cement. Cannula blocks were shortened to fit the desired length of the cannula (to prevent probing at unnecessary neural depths) and left in place post-surgery to prevent gliotic blockage of the guide cannulae. All surgeries took place approximately 1.5 weeks prior to testing to allow for adequate recovery.

\section{DATA COLLECTION}

All rats were handled daily and introduced to the testing environment multiple times during the week prior to testing. On the day of testing the cannulae blocks were removed and replaced by copperconstantan thermocoupled probes (Physitemp: www.physitemp. com) that extended $1 \mathrm{~mm}$ beyond the guide cannula. These probes have been used to record temperature from freely moving rats in brain areas such as the dorsal and ventral striatum of the nucleus accumbens, ventral tegmental area, hippocampus, and cerebellum (Kiyatkin et al., 2002; Brown et al., 2003; Kiyatkin and Brown, 2003; Brown and Kiyatkin, 2004). Physitemp software captured voltage recordings from the thermocoupled probe every $0.1 \mathrm{~s}$ and converted them into temperature readings.

Once the probe was secured, animals were placed in a Plexiglas testing box with two adjacent walls lined with mirrors. A video recorder was positioned outside the testing box at the corner of the non-mirrored walls to capture behaviors that occurred while the animal was facing the camera as well as behaviors reflected in the mirrors while the animal was facing away from the camera. Behavioral and temperature data were collected simultaneously during a single 2-h testing session between the hours of 12:00 pm and 6:00 pm. A digital stopwatch was synchronized with the temperature data acquisition software and placed next to the testing chamber in view of the video camera. After $2 \mathrm{~h}$ of continuous recording, the thermocoupled probe was removed from the guide cannula and replaced by the cannula block. The videos were then viewed by two independent, trained observers who were blind to the testing procedure. These observers documented the exact time in minutes and seconds of all spontaneous yawns and stretches. An investigator then reviewed each documented yawn and stretch to ensure that each yawn met the operationally defined criteria of gaping mouth and eye closure.

\section{RESULTS}

A total of 21 yawns were recorded from the four rats. As shown in Figure 1 the slope of temperature regressed against time changed significantly surrounding the onset of a yawn, first shifting in a positive direction at $1 \mathrm{~min}$ prior to yawning $[\beta=0.002, t(1216)=2.11$, $p=0.035]$ and then in a negative direction at the time of yawning $[\beta=-0.002, t(1216)=2.61, p<0.001]$.

In addition, 22 stretches were recorded. Eight of these stretches accompanied a yawn $(\mathrm{Y}+\mathrm{S})$, leaving 14 stretching-only events $(\mathrm{S})$, and 13 yawning-only events (Y). Table 1 shows each animal's contribution to the dataset. Most yawns (all but one) and all stretches occurred during the last hour of testing, while exploration tended to occur more often during the first hour. Average brain temperatures $\mathrm{M}(\mathrm{SD})$ in degrees Celcius for the first and second hours, respectively, for each animal are as follows: animal 1: 36.69 (0.26), $36.21(0.13)$; animal 2: $37.5(0.1), 37.1(0.26)$; animal 3: $37.13(0.29), 36.23(0.17)$, animal 4: 36.89 (0.33), $36.43(0.12)$. 


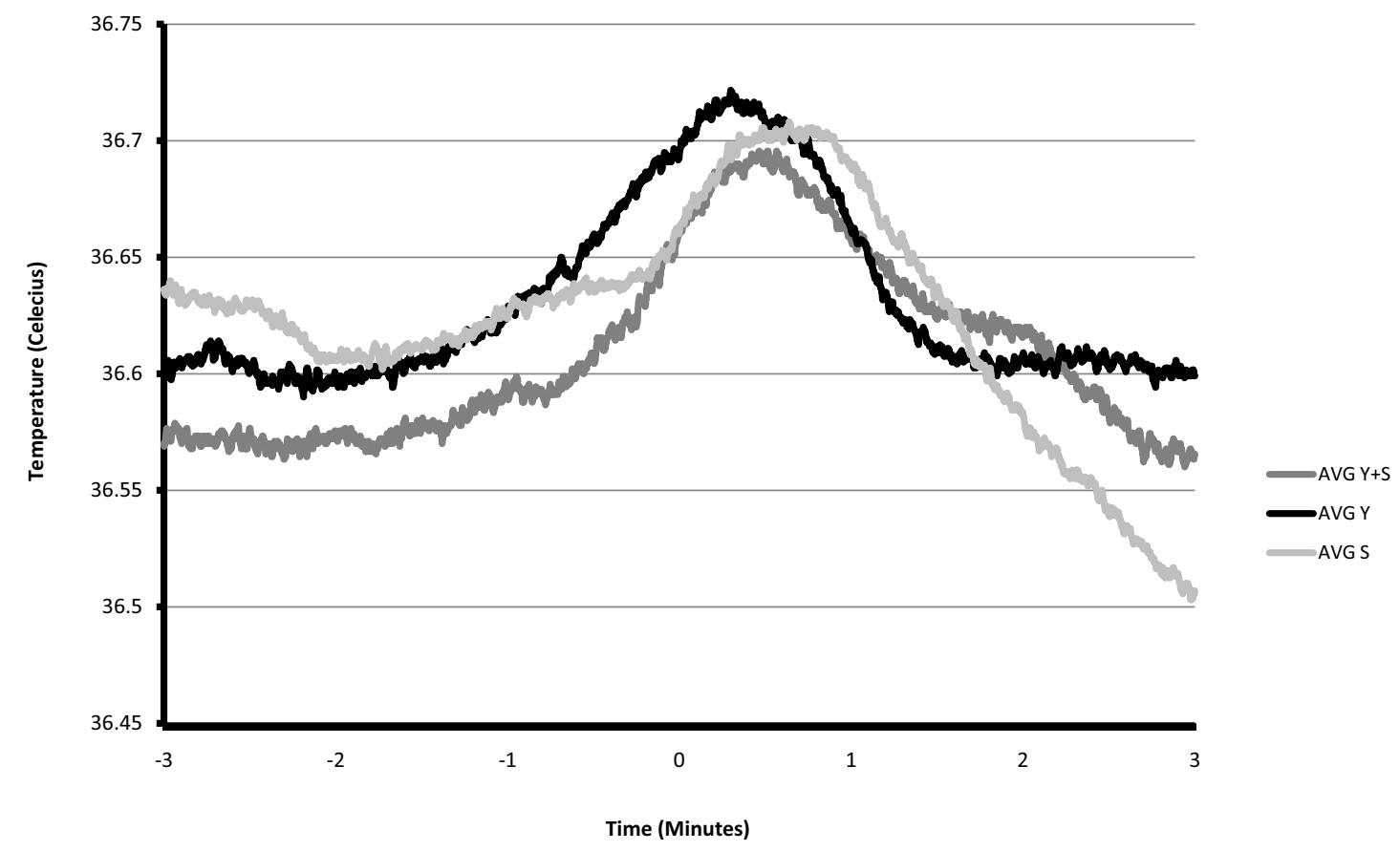

FIGURE 1 |Average brain temperature during the 3 min preceding and following a yawn $(n=13)$, stretch $(n=14)$, and yawn-stretch combination ( $n=8)$. Events are mutually exclusive.

Table 1 | Number of events recorded per animal. Events are mutually exclusive.

\begin{tabular}{llll}
\hline Animal & Yawns & Stretches & Yawns + stretches \\
\hline 1 & 1 & 5 & 1 \\
2 & 5 & 4 & 1 \\
3 & 2 & 1 & 0 \\
4 & 5 & 4 & 6 \\
\hline
\end{tabular}

Figure 1 depicts average brain temperature across the $3 \mathrm{~min}$ preceding and following the average of $\mathrm{Y}, \mathrm{S}$, and $\mathrm{Y}+\mathrm{S}$. A paired $t$-test comparing the changes in brain temperature $3 \mathrm{~min}$ prior to each of these events to the temperature changes during the $3 \mathrm{~min}$ after, revealed significant changes for all three, with $\mathrm{Y}$ having the greatest effect size: [Y: $t(12)=2.788, p=0.016$, Cohen's $d=1.546$; $\mathrm{Y}+\mathrm{S}: t(7)=2.403, p=0.047$, Cohen's $d=1.123$; $\mathrm{S}: t(13)=3.723$, $p=0.003$, Cohen's $d=1.027]$. The change in brain temperature prior to an event was calculated by subtracting the temperature at the onset of the event from the temperature $3 \mathrm{~min}$ prior to the event. Similarly, the change in brain temperature during the $3 \mathrm{~min}$ following the event was calculated by subtracting the temperature $3 \mathrm{~min}$ following the onset of the event from the temperature at the onset of the event. The average cooling following a yawn was $-0.11^{\circ} \mathrm{C}$, which in humans would amount to approximately $22 \%$ of the estimated daily circadian variance in brain temperature (Landolt et al., 1995). This is a conservative estimate of the magnitude of temperature decrease associated with a yawn, as brain temperature continues to increase until approximately $18 \mathrm{~s}$ after the onset of the average Y. Likewise, peak brain temperature occurred approximately $38 \mathrm{~s}$ following the average S and $28 \mathrm{~s}$ following a Y + S. Although decreases in temperature appear sooner following a yawn, the latencies were not significantly different [one-way ANOVA: $F(2,34)=2.883$, $p=0.071]$. Average temperatures (along with average standard errors) in degrees Celsius across the $6 \mathrm{~min}$ surrounding the events were as follows: $\mathrm{Y}=36.63(0.11), \mathrm{S}=36.62(0.10), \mathrm{Y}+\mathrm{S}=36.61$ (0.09), and these differences were not significant.

A detailed analysis of brain temperature from one representative animal over a 30 -min period revealed that the maximum temperature of $36.89^{\circ} \mathrm{C}$ was only reached once, immediately following a $\mathrm{Y}+\mathrm{S}$. All increases in brain temperature of $0.1^{\circ} \mathrm{C}$ or larger corresponded to yawning and stretching time points. Conversely, all rapid decreases in temperature of $0.5^{\circ} \mathrm{C}$ or larger occurred during the first minute following yawns only. This 30 -min time period captured brain temperatures during a range of behaviors and movements, including sleeping and investigative activity.

\section{DISCUSSION}

This is the first report of a systematic association between yawning, stretching and brain temperature. Increased brain temperature occurred prior to, and was predictive of the onset of yawning and/ or stretching, while decreases in brain temperature always followed the execution of each of these behaviors.

The current study is an initial step in exploring the thermal consequences of yawning and stretching. Although we gathered data on 13 yawns, 14 stretches and 8 yawn-stretch combinations there are limitations associated with our relatively small sample of animals. As a correlational study, it is possible that the observed rise in brain temperature may not trigger yawns or stretches per se, but instead may be an inherent property of the yawn/stretch process. Pre-yawning and pre-stretching processes, such as changes in blood 
flow or fluctuations in hormones and/or neurotransmitters, may contribute to the observed increase in brain temperature. If so, these data would be consistent with prior suggestions that yawning and stretching are associated with arousal during state change through increased blood flow (Greco and Baenninger, 1991) to the cavernous sinus surrounding the internal carotid artery (Matikainen and Elo, 2008), which then supplies cooled blood to cortical structures. Decreases in brain temperature following a yawn may be the physiological mechanism mediating cortical arousal (Baenninger, 1997). Because we measured brain temperature from a shallow cortical structure, future research in this area should gather either independent or simultaneous measurements from deeper structures, including the hypothalamus, which regulates body temperature.

We feel confident that our findings are not a result of movement artifacts during the act of yawning or stretching. Guide cannulae were secured in place by cranial screws and dental cement. Temperature changes of this steady, systematic nature were not observed during periods of activity other than yawning or stretching. Furthermore, as shown in Figure 1, the changes in temperature that portend the occurrence of yawning/stretching occur well in advance of the act itself, and the changes in temperature that follow the act continue for several minutes afterward.

Consistent with the thermoregulatory hypothesis, our findings suggest that both yawning and stretching may be responses to, or symptoms of transient brain hyperthermia. These behaviors may be acting either independently or in tandem to counter intermittent increases in brain temperature and promote thermal homeostasis. Differences in the nature of these behaviors, however, suggest that stretching may facilitate more widespread cooling compared to direct brain and head cooling associated with yawning. Future studies could investigate this by simultaneously measuring core body and brain temperature during yawning and stretching. The hypothesis that yawning acts to cool the brain (Gallup and Gallup Jr., 2007) is powerful because it integrates much seemingly diverse information about yawning from a variety of species, and it can also be used to generate testable predictions regarding the endogenous and exogenous conditions that affect yawning.

The association between yawning and sleep can be further understood from a thermoregulatory viewpoint. Length of sleep varies inversely with body temperature, and yawning frequently occurs before sleep onset in the evening when brain temperature is at its peak, and upon waking when brain temperature begins increasing from its lowest point (Provine et al., 1987a; Landolt et al., 1995). Prolonged sleep deprivation in rats has been shown to increase deep brain temperature (Everson et al., 1994), and excessive yawning is symptomatic of exhaustion/sleepiness. In humans, subjective ratings of sleepiness correlate with increases in skin temperature while lying down (Krauchi et al., 1997), and with increases in core body temperature when standing (Krauchi et al., 2005). Hot water consumption

\section{REFERENCES}

Argiolas, A., and Melis, M. R. (1998). The neuropharmacology of yawning. Eur. J. Pharmacol. 343, 1-16.

Askenasy, J. J. (1989). Is yawning an arousal defense reflex? J. Psychol. 123, 609-621.

Baenninger, R. (1987). Some comparative aspects of yawning in Betta splend-

increases body temperature as well as sleepiness, while ice intake produces the converse (Krauchi et al., 2006). Therefore, if variation in body temperature is associated with corresponding variation in sleepiness, our data may help explain why people often yawn when they are tired (Zilli et al., 2007). Unlike yawning, however, stretching is more likely to occur in the morning than the evening (Provine et al., 1987a), perhaps to promote more widespread arousal.

Given the ubiquitous nature of yawning, it is likely multifunctional across species. One potentially fruitful distinction for making predictions about the function of yawning may come from examination of the classification of homeothermic (birds, mammals) versus poikilothermic vertebrates (fish, amphibians, reptiles). Thus far, research illustrating the association between yawning and thermoregulation has been limited to the study of homeotherms, including experimental studies of birds, rats, and humans, and observational reports on non-human primates. Yawning may also play a role in behavioral thermoregulation among poikilotherms, however, the function of yawning in these species may be fundamentally different. Coupled with existing evidence supporting a connection between yawning and changes in internal and external temperatures, it is possible that yawning may also be a method of behavioral thermoregulation in a wide range of other species. Among homeotherms, ecological factors such as the need for water conservation could affect the way yawning is used to alleviate thermal stress, as has been suggested for budgerigars (Gallup et al., 2009). There could be differences in the function or frequency of yawning between homeothermic species adapted to unique thermal environments. In addition, this report documents equally strong temperature changes associated with stretching and yawning in rats, yet previous experimental studies in birds and rats have failed to show a relationship between thermoregulation and stretching (Gallup et al., 2009, 2010). Much like yawning, however, further research is needed to examine the impact of stretching on behavioral thermoregulation across species.

In closing, the present results suggest that excessive yawning may be a useful diagnostic tool for identifying instances of thermoregulatory dysfunction in humans (Gallup and Gallup Jr., 2008). Recent case studies have shown methods of behavioral cooling to postpone or eliminate symptoms of excessive yawning (Gallup Jr. and Gallup, 2010), and at least one report now highlights specific symptom relief from yawning in patients suffering from abnormal thermoregulation due to multiple sclerosis (Gallup et al., 2010). Therefore, the association between yawning and temperature change deserves further attention in clinical studies.

\section{ACKNOWLEDGMENTS}

We thank Dr. Eugene Kiyatkin of NIH for his shared expertise in brain temperature measurement and Dr. Richard Haase for statistical consultation.

MDMA ('ecstasy'): modulation by environmental conditions. Eur. J. Neurosci. 20, 51-58.

Brown, P. L., Wise, R. A., and Kiyatkin, E. A. (2003). Brain hyperthermia is induced by methamphetamine and exacerbated by social interaction. $J$. Neurosci. 23, 3924
Cabanac, M. (1993). Selective brain cooling in humans: "Fancy" or fact? FASEB J. 7, 1143-1146.

Campos, F. A., and Fedigan, L. M. (2009). Behavioral adaptations to heat stress and water scarcity in whitefaced capuchins (Cebus capucinus) in Santa Rosa National Park, Costa 
Rica. Am. J. Phys. Anthropol. 138, 101-111.

Caputa, M., Perrin, G., and Cabanac, M. (1978). Ecoulement sanguine reversible dans lab veine opthalamique: mechanisme de refroidissement selectif du cerveau humain. C. R. Acad. Sci. 87D, 1011-1014.

Cattaneo, L., Cucurachi, L., Chierici, E., and Pavesi, G. (2006). Pathological yawning as a presenting symptom of brain stem ischaemia in two patients. J. Neurol. Neurosurg. Psychiatry 77, 98-100.

Chen, C. H., and Lu, M. L. (2009). Venlafaxine-induced excessive yawning. Prog. Neuropsychopharmacol. Biol. Psychiatry 33, 156-157.

Collins, G. T., Newman, A. H., Grundt, P., Rice, K. C., Husbands, S. M., Chauvignac, C., Chen, J., Wang, S., and Woods, J. H. (2007). Yawning and hypothermia in rats: effects of dopamine D3 and D2 agonists and antagonists. Psychopharmacology (Berl.) 193, 159-170.

Daquin G., Micallef J., and Blin O. (2001). Yawning. Sleep Med. Rev. 5, 299-312.

Deklunder, G., Dauzat, M., Lecroart, J. L., Hauser, J. J., and Houdas, Y. (1991). Influence of ventilation of the face on thermoregulation in man during hyper- and hypothermia. Eur. J. Appl. Physiol. 62, 342-348.

Deputte, B. L. (1994). Ethological study of yawning in primates. I. Quantitative analysis and study of causation in two species of old world monkeys (Cercocebus albigena and Macaca fascicularis). Ethology 98, 221-245.

Everson, C. A., Smith, C. B., and Sokoloff, L. (1994). Effects of prolonged sleep deprivation on local rates of cerebral energy metabolism in freely moving rats. J. Neurosci. 14, 6769-6778.

Gallup,A.C. (2010)."A thermoregulatory behavior," in The Mystery of Yawning in Physiology and Disease, Vol. 28, ed. O. Walusinski, ed. (Basel, Switzerland: S. Karger AG - Medical and Scientific Publishers), 84-89.

Gallup, A. C., and Gallup, G. G. Jr. (2007). Yawning as a brain cooling mechanism: nasal breathing and forehead cooling diminish the incidence of contagious yawning. Evol. Psychol. 5, 92-101.

Gallup, A. C., and Gallup G. G. Jr. (2008). Yawning and thermoregulation. Physiol. Behav. 95, 10-16.

Gallup, A. C., Gallup, G. G. Jr., and Feo, C. (2010). Yawning, sleep, and symptom relief in patients with multiple sclerosis. Sleep Med. 11, 329-330.

Gallup, A. C., Miller, M. L., and Clark, A. B. (2009). Yawning and thermoregulation in budgerigars, Melopsittacus undulates. Anim. Behav. 77, 109-113.

Gallup, A. C., Miller, M. L., and Clark, A. B. (2010). The direction and range of ambient temperature influences yawning in budgerigars (Melopsittacus undulatus). J. Comp. Psychol. 124, 133-138.

Gallup, G. G. Jr., and Gallup, A. C. (2010). Excessive yawning and thermoregulation: two case studies of chronic, debilitating bouts of yawning. Sleep Breath 14, 157-159.

Greco, M., and Baenninger, R. (1991). Effects of yawning and related activities on skin conductance and heart rate. Physiol. Behav. 50, 1067-1069.

Guggisberg, A. G., Mathis, J., Hermann, U. S., and Hess, C. W. (2007). The functional relationship between yawning and vigilance. Behav. Brain Res. 179, 159-166.

Harris, B.A.,Andrews, P.J.D., and Murray, G. D. (2006). Enhanced upper respiratory tract airflow and head fanning reduce brain temperature in brain-injured, mechanically ventilated patients: a randomized, crossover, factorial trial. Br. J. Anaesth. 98, 93-99.

Hirashita, M., Shido, O., and Tanabe, M. (1992). Blood flow through the ophthalmic veins during exercise in humans. Eur. J. Appl. Physiol. 64, 92-97.

Kiyatkin, E. A., and Brown, P. L. (2003). Fluctuations in neural activity during cocaine self-administration: clues provided by brain thermorecording. Neuroscience 116, 525-538.

Kiyatkin, E. A., Brown, P. L., and Wise, R. A. (2002). Brain temperature fluctuation: a reflection of functional neural activation. Eur. J. Neurosci. 16, 164-168.

Krantz, M. J., Lee, J. K., and Spodick, D. H. (2004). Repetitive yawning associated with cardiac tamponade. Am. J. Cardiol. 94, 701-702.

Krauchi, K., Cajochen, C., and WirzJustice, A. (1997). A relationship between heat loss and sleepiness: effects of postural change and melatonin administration. J. Appl. Physiol. 83, 134-139.

Krauchi, K., Cajochen, C., and WirzJustice,A. (2005). Thermophysiological aspects of the three-process-model of sleepiness regulation. Clin. J. Sport Med. 24, 287-300

Krauchi, K., Vollenweider, S., Muller, S. Renz, C., Schachinger, H., and WirzJustice, A. (2006). Thermoregulatory dissociation of awareness and psychomotor vigilance. Sleep 29, A34 (Abstract Supplement).

Landolt, H. P., Moser, S., Wiesen, H. G., Borbeley, A. A., and Dijk, D. J. (1995). Intracranial temperature across 24 hour sleep wake cycles in humans. Neuroreport 6, 913-917.

Mariak, Z., White, M. D., Lewko, J., Lyson, T., and Piekarski, P. (1999). Direct cooling of the human brain by heat loss from the upper respiratory tract. J. Appl. Physiol. 87, 1609-1613.

Matikainen, J., and Elo, H. (2008). Does yawning increase arousal through mechanical stimulation of the carotid body? Med. Hypotheses 70, 488-492.
Provine, R. R. (1986). Yawning as a stereotyped action pattern and releasing stimulus. Ethology 72, 109-122.

Provine, R. R. (2005). Yawning. Am. Sci. 93, 532-539.

Provine, R. R., Hamernik, H. B., and Curchack, B. C. (1987a). Yawning: relation to sleeping and stretching in humans. Ethology 76, 152-160.

Provine, R. R., Tate, B.C., and Geldmacher, L. L. (1987b). Yawning: no effect of 3-5\% $\mathrm{CO}_{2}, 100 \% \mathrm{O}_{2}$, and exercise. Behav. Neural Biol. 48, 382-393.

Zajonc, R. B. (1985). Emotion and facial efference: a theory reclaimed. Science 288, 15-21.

Zenker, W., and Kubik, S. (1996). Brain cooling in humans - anatomical considerations. Anat Embryol. 193, 1-13.

Zilli I., Giganti F., and Salzarulo, P. (2007). Yawning in morning and evening types. Physiol. Behav. 91, 218-222.

Conflict of Interest Statement: The authors declare that the research was conducted in the absence of any commercial or financial relationships that could be construed as a potential conflict of interest.

Received: 18 March 2010; paper pending published: 18 June 2010; accepted: 18 August 2010; published online: 24 September 2010.

Citation: Shoup-Knox ML, Gallup AC Gallup GG Jr. and McNay EC (2010) Yawning and stretching predict brain temperature changes in rats: support for the thermoregulatory hypothesis. Front. Evol. Neurosci. 2:108. doi: 10.3389/ fnevo.2010.00108

Copyright (อ 2010 Shoup-Knox, Gallup, Gallup Jr. and McNay. This is an openaccess article subject to an exclusive license agreement between the authors and the Frontiers Research Foundation, which permits unrestricted use, distribution, and reproduction in any medium, provided the original authors and source are credited. 